\title{
Taper-based versus volume-based compatible estimating systems
}

DONALD D. MUNRO and JULIEN P. DEMAERSCHALK

Faculty of Forestry

University of British Columbio

Vancouver, B.C. V6T IW5

This paper describes some alternative methods to develop a compatible system of taper and volume. The advantages and disadvantages of the different alternatives are outlined. Methods to test the precision and accuracy of the systems are briefly discussed.

The volume of a tree, be it total or merchantable, is usually predicted using a volume curve or volume equation. The profile of a tree, i.e. the diameter inside or outside bark at any particular height above the ground, is usually predicted by using a taper curve or a taper equation. Uses of curves and equations for these purposes are well known and there is no need to discuss them in further detail.

Our purpose here is to discuss some special problems that may arise if taper and volume predictions must be made for the same trees using different predictive systems.

In a volume equation, volume is predicted as a function of diameter, height and occasionally some other tree characteristics:

$$
\mathrm{V}_{1}=\mathrm{f}_{1}\left(\mathrm{DBH}, \mathrm{HT}, \mathrm{X}_{\mathrm{i}}\right) \ldots \ldots \ldots \ldots \ldots
$$

where $\mathrm{V}_{1}=$ total or merchantable tree volume in cubic feet

$\mathrm{DBH}=$ diameter breast height outside bark in inches

HT = height of the tree in feet

$\mathrm{X}_{\mathrm{i}} \quad=$ any other tree characteristic e.g. form class, bark thickness, etc.

In a taper equation, diameter at any height is predicted as a function of diameter breast height, total height, section height and occasionally some other tree characteristics:

$$
\mathrm{d}=\mathrm{f}_{2}\left(\mathrm{DBH}, \mathrm{HT}, \mathrm{h}, \mathrm{X}_{\mathrm{i}}\right) \ldots \ldots \ldots \ldots \ldots{ }^{-}(2)
$$

where $\mathrm{d}=$ diameter inside bark at $\mathrm{h}$ above the ground in inches

$\mathrm{h}=$ height above the ground in feet

In this paper we presume that $X_{1}$ is not measured.

Volume of any part of the tree can be computed from equation (2) by integration between the appropriate limits.

$$
V_{0}=\int_{h_{1}}^{h_{2}}\left(\frac{\pi d^{2}}{4(144)}\right) d h \ldots \ldots \ldots \ldots .
$$

where $V_{s}=$ volume of a section of the tree between the heights $h_{1}$ and $h_{2}$ above the ground.
Sur les systèmes d'estimation du défilement comparés à ceux du volume des tiges. Cet article met en relief quelques méthodes pouvant développer un système acceptable sur la détermination du défilement et du volume des tiges. On y présente les avantages et les désavantages des diverses alternatives, et l'auteur discute des méthodes employées dans le but de vérifier la précision et l'exactitude des systèmes en cause.

Total volume of the tree is obtained by integration of (2) over the total tree length:

$$
V_{2}=\int_{0}^{\mathrm{H}}\left(\frac{\pi \mathrm{d}^{2}}{4(144)}\right) \mathrm{dh} \ldots \ldots \ldots \ldots \ldots
$$

Total volume can, of course, also be obtained directly from (1).

In the metric system, the variables could be measured in the following units:

$V_{1}, V_{2}$ and $V_{s}$ in cubic metres

$\mathrm{DBH}$ and $d$ in centimetres

$\mathrm{HT}$ and $\mathrm{h}$ in metres

Equation (3) must then be changed to

$$
V_{s}=\int_{h_{1}}^{h_{2}}\left(\frac{\pi d^{2}}{4\left(100^{2}\right)}\right) d h \ldots \ldots \ldots \ldots .
$$

Equation (4) should be modified similarly.

A volume equation of type (1), when used together with a taper equation of type (2), is called a taper and volume estimating system. The system of taper and volume estimation is called "compatible" if $V_{1}=V_{2}$ for all trees with the same $\mathrm{DBH}$ and HT. This means that integration of the taper equation must yield the same total volume as that given by the volume equation. When this is not the case, the system is said to be "incompatible".

Most systems in use are incompatible. Often, taper equations are used only to compute volumes of tips and stumps or to provide some specific information about the trees, such as diameter at a given height or the height for a given diameter. In such applications, incompatibility does not usually cause serious problems.

There are numerous situations, however, where incompatibility is very disturbing and a compatible system would be much more desirable. If one is interested in the volumes of different sections of the tree and one computes these by equation (3), it becomes embarrassing, to say the least, if, after adding the volumes of all sections, one gets a total volume that is different from the estimation for the same tree obtained in equation (1). This may be the case in biomass studies where various component volumes or weights of the tree are 
estimated individually, or simply in the case where one computes tip, stump and merchantable volume separately.

A compatible system, besides having obvious practical advantages, is also very appealing from a theoretical viewpoint. The most important benefit of a compatible system is that consistent results are obtained. Biologically and mathematically, taper and volume should not be considered independently, but rather as mathematically dependent quantities.

There are several ways to construct a compatible system. The two most important ones will be discussed here. The first may be called a taper-based system; the second a volume-based system.

In a taper-based system the first step is to fit a taper equation (2) to taper data. This equation can then be used directly for taper estimation. Equation (4), the integration of the taper equation over the total tree length, is then used to obtain total tree volume estimates. Thus in a taper-based system, basically only a taper equation is used. This method of constructing a compatible system is a very obvious one; the alternative method is less obvious, more complicated, but usually provides better estimates.

In a volume-based system, the first step is to fit a volume equation (1) to tree volume data. A taper equation (2) is then fitted to taper data from the same trees. The coefficients of this taper equation, however, are conditioned such that $\mathrm{V}_{1}=$ $V_{2}$ for all trees. The conditioning process which has been described recently (Demaerschalk 1972, $1973 a, 1973 b)$, assumes that the summation of volumes of tree segments derived from the taper equation is equal to the tree volume as estimated from the volume equation.

Because most taper equations which have been described in the past can be integrated to total volume, and because most volume equations in use can be converted to a compatible taper equation, there is a huge number of possible systems. The forester is left with the most complicated problem of selecting a good system for his particular case.

A good tree taper and volume estimating system should be unbiased for all tree sizes, in the estimation of diameter at any height, height of any diameter, volume of any section and total tree volume. It should also provide the required maximum confidence intervals for each of these estimations.

Before accepting any particular system we must firstly check the bias and the standard error of estimate of diameter estimation at the different heights. Secondly if, from a transformation of the taper equation, heights will be estimated for given diameters, the bias and the standard error of estimate of the height estimation must be tested as well. Thirdly, the estimation of the volumes of tree sections and total tree volume must be checked. The bias and precision of the estimation of tree section volumes will depend on the way the sections are defined. Section limits may be defined in terms of heights, in terms of diameters or in a mixed way. These different ways must be tested separately. Also, all these tests should be carried out for the different tree size classes separately.

There is no such thing as the best system. Both taper-based and volume-based systems, have some advantages and disadvantages and these depend upon the particular equation used. Confounding results may be observed from one species to another and from one size class to another.

\section{Taper-based systems}

The precision and the accuracy of a taper-based estimating system depends entirely on the accuracy of the taper equation. A totally unbiased taper equation does not exist. Bias in diameter estimation has different effects on the bias in volume depending on the size of the tree and the section height to which volume is estimated.

Many taper equations, especially the ones without an inflection point, tend to underestimate the butt section, overestimate the lower tree section, underestimate the upper tree section and overestimate the top of the tree. This must be taken into consideration in the estimation of section volumes.

The so-called, sigmoid taper equations with an inflection point do not solve the problem of bias. Their pattern of bias, usually, is entirely different. Bias is often smaller near the base of the tree but usually much bigger in the upper parts of the tree.

Although a taper equation may look reasonably good for taper estimation, the volume estimation may be entirely inadequate since bias of taper near the base of the tree has a totally different effect on volume from a bias of taper near the top of the tree. As a matter of fact, very few taper-based systems provide reasonably satisfactory results for both taper and volume estimation.

\section{Volume-based systems}

Volume-based systems, if derived from sufficiently unbiased volume equations will, of course, always be satisfactory for total volume estimation. Unfortunately however, most volume-based taper equations have no inflection point. As a result, they have a systematic bias for diameter estimation as mentioned above. In general, however, this bias is not greater than that for the taper-based taper equations.

If, however, the original volume equation is biased, the taper prediction will probably become entirely unreliable.

The patterns of bias in diameter are seldom identical for all the size classes but rather shift from one class to another. This makes a percentage correction extremely difficult, if not impossible.

Height estimation from a transformed taper equation must be approached with extreme caution. A bias of 0.1 inch in diameter may result in a bias of more than 1 foot in height. This causes serious errors in the volume estimation of sections, particularly where the section limits are defined as diameters and the corresponding heights must be estimated from the transformed equation. 
The results of our research indicate that some taper and volume systems developed more than half a century ago, are nearly as good as some which have been developed recently with the aid of modern high speed electronic computers.

Obviously the pencil, graph paper and alignment charts served these early investigators well. Indeed, perhaps the time has come to ask ourselves if we are proceeding on the wrong track!

\section{Literature cited}

DEMAERSCHALK, J. P. 1972. Converting volume equations to compatible taper equations. Forest Sci. 18: 241-245.

DEMAERSCHALK, J. P. 1973a. Integrated systems for the estimation of tree taper and volume. Can. J. Forest. Res. 3: 90-94.

DEMAERSCHALK, J. P. 1973b. Compatible tree taper and volume estimating systems. Fac. Forest., Univ. British Columbia, Ph.D. thesis. 131 p.

\section{EDWARD}

\section{FELLOWS}

\section{FORESTRY \& FOREST PRODUCTS CONSULTANT}

P.O. Box 354, 461 King St., FREDERICTON, N. B.

Registered Professional Forester (N. B.)

MEMBER:

Canadian Institute of Forestry

Forest Products Research Society, Etc.

INDUSTRY DEVELOPMENT - FOREST PRODUCTS ECONOMIC FOREST POLICY \& ADMINISTRATION

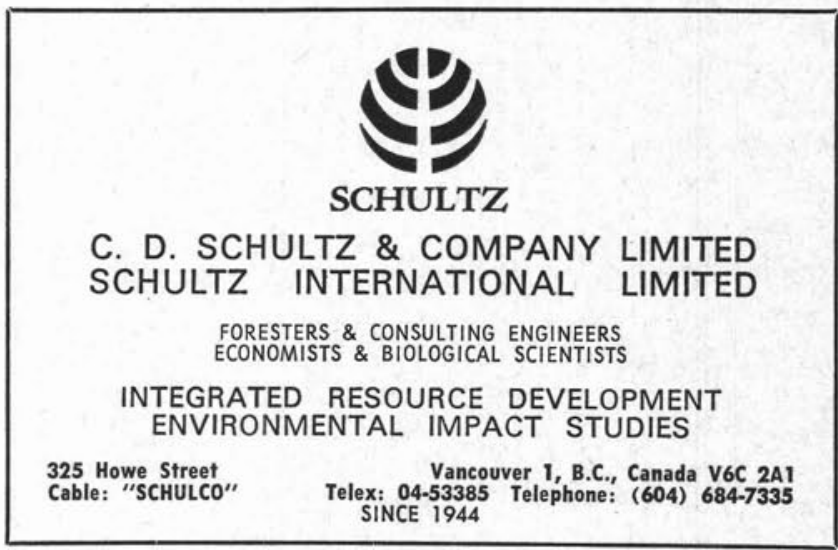

Do you have copies of these publications by the Canadian Institute of Forestry / Institut forestier du Canada? If not, you are missing out on some very useful information. Copies may be obtained by writing to: The Canadian Institute of Forestry, Box 5000, Macdonald College, Quebec.

\section{Expanding Forestry Horizons}

K. G. Fensom describes 60 years of forestry in Canada as seen by the parade of hopes and fears, agreements and differences, and frustrations and accomplishments of a nationwide organization of foresters. 547 p. 1972.

\section{Forestry Education in Canada}

This 408-page book is the result of extensive study by Dr. G. A. Garratt, Dean Emeritus, Yale University School of Forestry, conducted at the request of the Canadian Institute of Forestry. 1971.

\section{The Forestry Chronicle Cumulative Index}

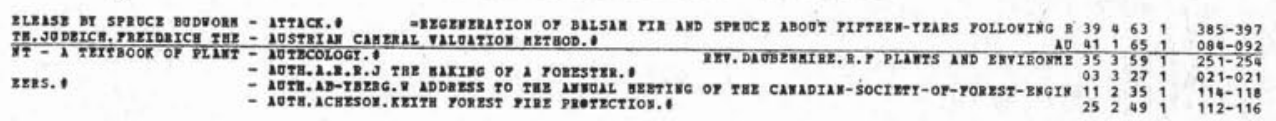

Cumulative keyword and cumulative table of contents, volumes 1-44. 